\title{
Psychosis in behavioral variant frontotemporal dementia
}

\author{
This article was published in the following Dove Press journal: \\ Neuropsychiatric Disease and Treatment \\ 13 April 2017 \\ Number of times this article has been viewed
}

\author{
Flora T Gossink $k^{1,2}$ \\ Everard GB Vijverberg ${ }^{2,3}$ \\ Welmoed Krudop ${ }^{2}$ \\ Philip Scheltens ${ }^{2}$ \\ Max L Stek' \\ Yolande AL Pijnenburg ${ }^{1,2}$ \\ Annemiek Dols ${ }^{1,2}$ \\ 'Department of Old Age \\ Psychiatry, GGZinGeest, ${ }^{2}$ Alzheimer \\ Center \& Department of Neurology, \\ VU University Medical Center, \\ Amsterdam, ${ }^{3}$ Department of \\ Neurology, HagaZiekenhuis, \\ The Hague, the Netherlands
}

Correspondence: Flora T Gossink Department of Old Age Psychiatry, GGZinGeest, De Nieuwe Valerius, Amstelveenseweg 589, I08I JC

Amsterdam, the Netherlands

$\mathrm{Tel}+3$ I 6I 4028518

Fax +3। 204448529

Email f.gossink@vumc.nl
Background: Dementia is generally characterized by cognitive impairment that can be accompanied by psychotic symptoms; for example, visual hallucinations are a core feature of dementia with Lewy bodies, and delusions are often seen in Alzheimer's disease. However, for behavioral variant of frontotemporal dementia (bvFTD), studies on the broad spectrum of psychotic symptoms are still lacking. The aim of this study was to systematically and prospectively subtype the wide spectrum of psychotic symptoms in probable and definite bvFTD.

Methods: In this study, a commonly used and validated clinical scale that quantifies the broad spectrum of psychotic symptoms (Positive and Negative Symptom Scale) was used in patients with probable and definite bvFTD $(n=22)$ and with a primary psychiatric disorder $(n=35)$ in a late-onset frontal lobe cohort. Median symptom duration was 2.8 years, and the patients were prospectively followed for 2 years.

Results: In total, $22.7 \%$ of bvFTD patients suffered from delusions, hallucinatory behavior, and suspiciousness, although the majority of the patients exhibited negative psychotic symptoms such as social and emotional withdrawal and blunted affect (95.5\%) and formal thought disorders (81.8\%). "Difficulty in abstract thinking" and "stereotypical thinking" (formal thought disorders) differentiated bvFTD from psychiatric disorders. The combined predictors difficulty in abstract thinking, stereotypical thinking, "anxiety", "guilt feelings," and "tension" explained 75.4\% of variance in the diagnosis of bvFTD versus psychiatric diagnoses $(P<0.001)$.

Conclusion: Delusions, hallucinatory behavior, and suspiciousness were present in one-fifth of bvFTD patients, whereas negative psychotic symptoms such as social and emotional withdrawal, blunted affect, and formal thought disorders were more frequently present. This suggests that negative psychotic symptoms and formal thought disorders have an important role in the psychiatric misdiagnosis in bvFTD; misdiagnosis in bvFTD might be reduced by systematically exploring the broad spectrum of psychiatric symptoms.

Keywords: frontotemporal dementia, psychosis, schizophrenia, formal thought disorders

\section{Introduction}

The behavioral variant of frontotemporal dementia (bvFTD) is the second most common early onset dementia and the most prevalent form of frontotemporal lobar degeneration. ${ }^{1,2}$ The clinical presentation of bvFTD has a wide range of symptoms, including prominent neuropsychiatric symptoms that often mimic psychiatric disorders. ${ }^{3,4}$ Various studies described the overlapping symptoms between bvFTD and psychiatric disorders, resulting in frequent misdiagnoses, with psychosis as one of the most common. . $^{5-8}$

Although delusions are often present in Alzheimer's disease and visual hallucinations are a core feature of dementia with Lewy bodies, studies on the broad spectrum of 
psychotic symptoms in bvFTD are still lacking. ${ }^{9,10}$ As defined by the classification criteria, symptoms of psychosis are classified as positive and negative and formal thought disorders. ${ }^{11}$ Positive psychotic symptoms refer to an excess or distortion of normal functions (eg, paranoia or hearing voices), negative symptoms reflect a diminution or loss of normal functions (eg, reduced motivation or reduced emotion), and formal thought disorders implicit a disorganization of thought. ${ }^{12-14}$ Previous studies on psychotic symptoms in bvFTD were focused only on positive psychotic symptoms (eg, hallucinations, delusions, and paranoia) and found that these psychotic features were present in 10\%-32\% of bvFTD patients. ${ }^{3,15-17}$ Even though negative psychotic symptoms and formal thought disorders have led to frequent misdiagnosis of psychosis in bvFTD patients, comprehensive studies on the full spectrum of psychosis in bvFTD are lacking. ${ }^{5,8,18-20}$ Although the distinction between bvFTD and psychiatric disorders is a major diagnostic dilemma, especially in the early stages of disease, ${ }^{3,5,21}$ knowledge on psychotic symptoms in bvFTD based on this common broad definition of psychosis cannot be ignored. In one of the previous papers, ${ }^{22}$ the authors of the present study found that a positive history of psychiatric illness, male gender, lower Stereotypy Rating Inventory (SRI) scores, and higher Montgomery-Asberg Depression Scale scores were predictors of the diagnosis of a psychiatric disorder versus bvFTD, but a systematic prospective study on the broad definition of psychosis in bvFTD has not been published yet. Whether specific psychotic symptoms of bvFTD are unique and they can distinct bvFTD from psychiatric disorders, and vice versa, would help the clinician considerably in daily practice from a diagnostic perspective.

The aim of the present study was twofold: first, whether specific psychotic symptoms characterize bvFTD was investigated; and second, whether, despite clinical overlap, specific psychotic symptoms could distinguish bvFTD from a psychiatric disorder was studied. A commonly used and validated clinical scale was used to find psychosis and schizophrenia symptoms (the Positive and Negative Symptom Scale [PANSS]), which quantifies the broad spectrum of psychotic symptoms including positive and negative psychotic symptoms and formal thought disorders. ${ }^{23,24}$ As the PANSS is originally developed to prospectively evaluate psychotic symptomatology over time, it also includes a general subscale, wherein symptoms such as tension and anxiety are included. ${ }^{25-27}$ The aim of the present study was to define psychotic symptoms in patients with probable and definite bvFTD in comparison with patients with a psychiatric disorder, all exhibiting a late-onset frontal lobe (LOF) syndrome. At baseline, the broad spectrum of psychotic symptoms including positive and negative psychotic symptoms, formal thought disorders, and general symptoms were determined. All the patients were followed up during a period of 2 years, and the clinical diagnosis after 2 years was used as the gold standard.

\section{Methods}

\section{Patients}

Subjects were the participants of the LOF study, a longitudinal multicenter prospective follow-up study aimed at identifying (prodromal) bvFTD among a cohort of patients with frontal neuropsychiatric features. All the patients were recruited through the memory clinic of the VU University Medical Center (VUmc), Amsterdam, Alzheimer Center, and the Old Age Psychiatry Department of GGZ inGeest, Amsterdam, the Netherlands (inpatient and outpatient), between April 2011 and June 2013. Inclusion and exclusion criteria had been described previously. ${ }^{21}$ Patients aged $\geq 45$ years were included when behavioral symptoms including apathy, disinhibition, and/or compulsive behavior dominated the clinical picture.

\section{Diagnostic procedure}

The study was approved by the Medical Ethics Committee of the VU University Medical Center, Amsterdam. Before inclusion, written informed consent was obtained from all the participants or, in case of incompetence of giving a fully informed consent by the participant, the caregiver or legal representative. All the patients underwent a standardized assessment, including medical history and family history; informant-based history, physical, neurological, and psychiatric examinations; neuropsychological assessment; laboratory tests; and magnetic resonance imaging (MRI) of the brain acquired on a 3T Signa HDxt scanner (GE Medical Systems, Milwaukee, WI, USA) following a standard MRI protocol for dementia. In case of normal or insufficiently explanatory MRI results (not explaining frontosubcortical dysfunction), a [18F] FDG-PET scan was performed by using EXACT HRp scanner (Siemens/CTI, Knoxville, TN, USA). Neurological and psychiatric evaluation was done by both a neurologist and an experienced geriatric psychiatrist. In a multidisciplinary consensus meeting, the neurologist and psychiatrist determined the diagnosis. These diagnoses were based on the Diagnostic and Statistical Manual of Mental Disorders, Fourth Edition for psychiatric disorders and the International bvFTD Criteria Consortium for bvFTD. ${ }^{11,23}$ All the subjects were genetically screened for the presence of a C9orf repeat expansion, given 
the great symptomatic overlap with psychiatric disorders and long disease courses that have been described in this mutation type. ${ }^{24,28}$ All the patients received at least 2 years of clinical follow-up, and the clinical diagnosis after 2 years was used as the gold standard.

In order to compare bvFTD patients with the most relevant diagnostic group with psychotic symptoms, of all the patients in the LOF study $(n=137)$, the group of patients with probable and definite bvFTD $(n=22)$ and patients with a primary psychiatric disorder $(n=35)$ were selected. Patients with other neurodegenerative, neurological, or general diseases and patients with vascular cognitive impairment, relational problems, or possible bvFTD were therefore not taken into account. In total, 15 patients who did not complete the PANSS due to motivational and logistic problems were excluded. Of the 22 patients diagnosed with probable and definite bvFTD, four patients were diagnosed with definite bvFTD consisting of two C9ORF72 hexanucleotide repeat expansion, one progranulin mutation, and one histopathologically confirmed tauopathy. Of the 35 patients with a clinical psychiatric diagnosis, two patients had schizophrenia, 11 were diagnosed with a major depressive disorder, four had a minor depressive disorder, six had a bipolar disorder, three had an autism spectrum disorder, one had an obsessive compulsive disorder, one had a general anxiety disorder, and seven had personality problems.

\section{Measurements}

At baseline, 30 symptoms, including positive psychotic symptoms, negative psychotic symptoms, formal thought disorders, and general psychopathology, were measured in patients diagnosed with probable and definite bvFTD and with a psychiatric disorder, by using the PANSS. ${ }^{26}$ Of the 30 items included in the PANSS, 7 items represent positive psychotic symptoms (ie, delusions, conceptual disorganization, hallucinatory behavior, excitement, grandiosity, suspiciousness, and hostility), 7 items represent negative psychotic symptoms (ie, blunted affect, emotional withdrawal, poor rapport, passive/apathetic social withdrawal, difficulty in abstract thinking, lack of spontaneity, and stereotypical thinking), and 16 items represent general psychopathology (ie, somatic concern, anxiety, guilt feelings, tension, mannerisms and posturing, depression, motor retardation, uncooperativeness, unusual thought content, disorientation, poor attention, lack of judgment/insight, disturbance of volition, poor impulse control, preoccupation, and active social avoidance). Formal thought disorders are defined by the items of conceptual disorganization, difficulty in abstract thinking, lack of spontaneity, and stereotypical thinking. ${ }^{14}$
The PANSS is widely used in patients with neuropsychiatric symptoms, and it has been found to have good sensitivity and specificity for psychosis and schizophrenia. ${ }^{25-27,29}$

The PANSS was administered as a $\sim 45$ min clinical interview. Patients were rated from 1 to 7 by a trained clinician regarding the 30 different symptoms, based on the interview with the patient as well as reports of family members about how the patients had functioned during the last week. ${ }^{26}$ The symptoms were rated on a 1-7 point scale, whereby 1 represents "the absence of symptoms" and 7 corresponds to "severe interference with daily life activities." ${ }^{25-27}$ All the included patients underwent the PANSS, performed by trained clinicians who were blind for the clinical diagnosis (WK and FG). These clinicians did not have information about previous medical history, neither other advanced medical information. The PANSS scores were not included in the clinical evaluation.

\section{Statistical analyses}

Statistical analyses were performed by using the Statistical Package for the Social Sciences (for Windows; IBM, Armonk, NY, USA), Version 21. Group differences on sociodemographic variables were investigated by using independent $t$-tests and $\chi^{2}$ tests. Overall percentages of patients with psychotic symptoms were defined by counting all the patients who had symptoms at the positive or negative subscale score of $\geq 3$, as a rating of 3 is indicative of a symptom whose presence was clearly established and interferes in day-to-day functioning. ${ }^{27,30}$

Group differences on symptoms of PANSS were measured by using Mann-Whitney $U$-test. A $P$-value of $<0.01$ was considered statistically significant. Furthermore, univariate logistic regression analyses were performed with diagnosis as a dependent variable. Variables with $P$-values $<0.01$ were selected, and in the next step, these variables were combined with a multivariate model to investigate the explained variance. Potential multicollinearity was investigated using the variance inflation factor $<5$ for each of the independent variables in the multivariable model by using linear regression analyses.

\section{Results \\ Clinical and demographic data}

Table 1 lists demographic data of the diagnostic groups. Patients were predominantly Caucasian $(>90 \%)$ and male $(>60 \%)$. Regarding symptom duration, education, the total score at the Mini-Mental State Examination, frontal 
Table I Demographics

\begin{tabular}{|c|c|c|c|}
\hline \multirow[t]{2}{*}{ Demographic and clinical characteristics } & \multirow[t]{2}{*}{ bvFTD, n=22 } & \multirow{2}{*}{$\begin{array}{l}\text { Psychiatric } \\
\text { diagnosis, } n=35\end{array}$} & \multirow{2}{*}{$\begin{array}{l}\text { Statistics } \\
\chi^{2} / \text { t-test/MW } \\
\text { (df) P-value }\end{array}$} \\
\hline & & & \\
\hline Age: mean (SD) & $63.04(6.18)$ & $58.95(6.67)$ & $0.84(55) 0.03$ \\
\hline Gender: male \% & 63.64 & 80.00 & $\mathrm{I} .87(\mathrm{I}) 0.17$ \\
\hline Symptom duration: median (IQR) & $3.00(5.50)$ & $3.00(1.00)$ & 0.68 \\
\hline \multicolumn{4}{|l|}{ Education } \\
\hline Low, \% & 18.18 & 21.43 & $0.69(2) 0.7 \mathrm{I}$ \\
\hline Middle, \% & 50.00 & 57.14 & \\
\hline High, \% & 31.82 & 21.43 & \\
\hline MMSE: mean (SD) & $26.14(2.80)$ & $25.91(2.54)$ & $0.36(55) 0.76$ \\
\hline FAB: mean (SD) & $14.29(4.20)$ & $|5.4|(2.64)$ & $0.11(53) 0.23$ \\
\hline SRI: median (IQR) & $16.50(15.00)$ & $4.00(8.00)$ & $<0.001$ \\
\hline FBI: mean (SD) & $26.14(10.86)$ & $24.77(8.70)$ & $0.48(55) 0.60$ \\
\hline \multicolumn{4}{|l|}{ PANSS } \\
\hline Total score: mean (SD, range) & $59.5(14.0,35-87)$ & $61.1(13.6,37-108)$ & $0.03(55) 0.67$ \\
\hline Total positive subscale: median (SD, range) & $10.32(2.9,7-18)$ & $11.66(3.5,7-25)$ & $0.36(55) 0.14$ \\
\hline Total negative subscale: median (IQR, range) & $21.0(13.0,8-34)$ & $18.0(6.0,9-33)$ & $(\mathrm{MW}) 0.04 \mathrm{I}$ \\
\hline Total general subscale: median (SD, range) & $28.0(6.1,19-42)$ & $32.0(7.7,18-58)$ & $0.57(55) 0.046$ \\
\hline $\mathrm{n}(\%)$, number of patients with psychotic symptoms (PANSS P \& N $\geq 3$ ) & $21(95.5)$ & $34(97.1)$ & $0.11(1) 0.74$ \\
\hline $\begin{array}{l}\mathrm{n}(\%), \text { number of patients with delusions, hallucinatory behavior, and/or } \\
\text { suspiciousness }^{\mathrm{a}}\end{array}$ & $5(22.7)$ & $15(42.9)$ & $2.40(I) 0.12$ \\
\hline $\mathrm{n}(\%)$, number of patients with negative psychotic symptoms ${ }^{b}$ & $21(95.5)$ & $34(97.1)$ & $0.11(I) 0.74$ \\
\hline $\mathrm{n}(\%)$, number of patients with formal thought disorders ${ }^{c}$ & $18(81.8)$ & $23(65.7)$ & $1.74(I) 0.19$ \\
\hline
\end{tabular}

Notes: Education: low, less than 4 years of low- or average-level secondary education; middle, 4 years of low- or average-level secondary education; high, 5 years of high-level

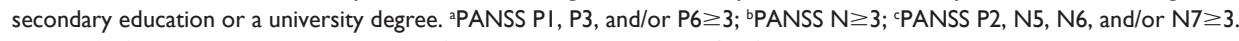

Abbreviations: bvFTD, behavioral variant frontotemporal dementia; FAB, frontal assessment battery; FBI, Frontal Behavioral Inventory; IQR, interquartile range; $d f$, degrees of freedom; KW, Kruskal-Wallis test; MMSE, Mini-Mental State Examination; MW, Mann-Whitney U-test; PANSS, Positive and Negative Symptom Scale; SD, standard deviation; SRI, Stereotypy Rating Inventory.

assessment battery, and Frontal Behavioral Inventory, the groups did not differ $(P>0.05)$. Patients with probable and definite bvFTD were significantly older $(P=0.03)$ and had a higher total score at the SRI compared with patients with a psychiatric diagnosis $(P<0.001)$.

\section{Psychotic symptoms in bvFTD and psychiatric disorders}

In $95.5 \%$ of the patients with probable and definite bvFTD, at least one of the psychotic symptoms was present (score $\geq 3$; Table 1). BvFTD patients were characterized not by positive psychotic symptoms but by negative psychotic symptoms and formal thought disorders (ie, blunted affect, emotional withdrawal, poor rapport, apathetic social withdrawal, difficulty in abstract thinking, and stereotypical thinking) and items from the general subscale (Table 2). In total, $22.7 \%$ of bvFTD patients had delusions, hallucinatory behavior, and suspiciousness, whereas the majority of bvFTD patients exhibited negative psychotic symptoms (95.5\%) and formal thought disorders (81.8\%; Table 1).
In $97.1 \%$ of the patients with a psychiatric disorder, psychotic symptoms were present, from both the positive and the negative subscales (Table 1). Symptoms from the general subscale were also present in patients with a psychiatric disorder (Table 2).

\section{Psychotic symptoms in bvFTD versus psychiatric disorders}

The total score of the positive subscale of the PANSS was not different between bvFTD patients and patients with a psychiatric disorder. The total score of the negative subscale of the PANSS was significantly higher in patients with bvFTD than in patients with a psychiatric disorder (21.0 versus $18.0 ; P=0.041$; Table 1 ).

By using logistic regression, a diagnosis of probable or definite bvFTD was associated with difficulty in abstract thinking (odds ratio $[\mathrm{OR}]=1.86,95 \%$ confidence interval $[\mathrm{CI}]=1.22-$ 2.84, $P=0.004)$ and stereotypical thinking $(\mathrm{OR}=1.83,95 \%$ $\mathrm{CI}=1.21-2.76, P=0.004)$, which both represent formal thought disorders. These symptoms distinguished patients with bvFTD from patients with a psychiatric disorder (Table 3). 
Table 2 Psychotic symptoms in bvFTD patients and patients with psychiatric diagnosis

\begin{tabular}{|c|c|c|c|}
\hline $\begin{array}{l}\text { Symptoms, } \\
\text { median (IQR) } \\
\text { range }\end{array}$ & $\begin{array}{l}\text { bvFTD } \\
(n=22)\end{array}$ & $\begin{array}{l}\text { Psychiatric } \\
\text { diagnosis } \\
(n=35)\end{array}$ & $P$-value \\
\hline \multicolumn{4}{|c|}{ Positive psychotic symptoms } \\
\hline PI Delusions & $|(0)|-3$ & I (I) I-5 & $M W=0.05$ \\
\hline $\begin{array}{l}\text { P2 Conceptual } \\
\text { disorganization }\end{array}$ & $2(2) I-4$ & I (2) I-5 & $M W=0.18$ \\
\hline $\begin{array}{l}\text { P3 Hallucinatory } \\
\text { behavior }\end{array}$ & I (0) I-2 & I (0) I-4 & $\mathrm{MW}=0.54$ \\
\hline P4 Excitement & I (2) I-4 & $3(2) I-4$ & $M W=0.03$ \\
\hline P5 Grandiosity & I (I) I-4 & I (0) I-3 & $\mathrm{MW}=0.02$ \\
\hline P6 Suspiciousness & I (0) I-4 & $2(2) 1-5$ & $M W=0.05$ \\
\hline P7 Hostility & $|(0)|-3$ & I (I) I-3 & $M W=0.03$ \\
\hline \multicolumn{4}{|c|}{ Negative psychotic symptoms } \\
\hline NI Blunted affect & $3(2) \mathrm{I}-7$ & $3(1) \mathrm{I}-7$ & $M W=0.78$ \\
\hline $\begin{array}{l}\text { N2 Emotional } \\
\text { withdrawal }\end{array}$ & $3(1) I-6$ & $3(1) 1-6$ & $M W=0.78$ \\
\hline N3 Poor rapport & $4(3) \mathrm{I}-6$ & $3(I) I-6$ & $M W=0.10$ \\
\hline $\begin{array}{l}\text { N4 Apathetic } \\
\text { social withdrawal }\end{array}$ & $3(2) I-5$ & $3(2) I-6$ & $M W=0.56$ \\
\hline $\begin{array}{l}\text { N5 Difficulty in } \\
\text { abstract thinking }\end{array}$ & $3(3) I-6$ & I (2) I-4 & $M W=0.004$ \\
\hline $\begin{array}{l}\text { N6 Lack of } \\
\text { spontaneity }\end{array}$ & I (3) I-5 & I (I) I-5 & $M W=0.4 \mathrm{I}$ \\
\hline $\begin{array}{l}\text { N7 Stereotypical } \\
\text { thinking }\end{array}$ & $3(4) I-7$ & I (I) I-5 & $M W=0.005$ \\
\hline \multicolumn{4}{|l|}{ General subscale } \\
\hline $\begin{array}{l}\text { GI Somatic } \\
\text { concern }\end{array}$ & I (I) I-5 & I (2) I-6 & $M W=0.37$ \\
\hline G2 Anxiety & I (0) I-3 & $2(2) I-5$ & $M W=0.00 \mathrm{I}$ \\
\hline G3 Guilt feelings & I (0) I-3 & $2(2) I-6$ & $M W=0.003$ \\
\hline G4 Tension & I (0) I-3 & $3(2) \mathrm{I}-6$ & $M W=0.000$ \\
\hline $\begin{array}{l}\text { G5 Mannerisms } \\
\text { and posturing }\end{array}$ & I (0) I-3 & I (0) I-3 & $\mathrm{MW}=0.74$ \\
\hline G6 Depression & I (2) I-5 & $3(4) \mathrm{I}-7$ & $M W=0.015$ \\
\hline $\begin{array}{l}\text { G7 Motor } \\
\text { retardation }\end{array}$ & I (2) I-4 & I (2) I-4 & $M W=0.78$ \\
\hline $\begin{array}{l}\text { G8 Uncooper- } \\
\text { ativeness }\end{array}$ & I (2) I-5 & I (I) I-4 & $M W=0.82$ \\
\hline $\begin{array}{l}\text { G9 Unusual } \\
\text { thought content }\end{array}$ & I (0) I-3 & I (0) I-3 & $M W=0.8 I$ \\
\hline GI0 Disorientation & I (0) I-6 & $|(I)|-3$ & $M W=0.57$ \\
\hline $\begin{array}{l}\text { GII Poor } \\
\text { attention }\end{array}$ & I (I) I-4 & I (2) I-5 & $M W=0.69$ \\
\hline $\begin{array}{l}\text { GI2 Lack of } \\
\text { judgment/insight }\end{array}$ & $3(1) 1-6$ & $3(2) I-6$ & $M W=0.02$ \\
\hline $\begin{array}{l}\text { GI3 Disturbance } \\
\text { of volition }\end{array}$ & I (2) I-4 & I (0) I-5 & $M W=0.64$ \\
\hline $\begin{array}{l}\text { GI4 Poor impulse } \\
\text { control }\end{array}$ & $3(2) I-5$ & $3(I) I-5$ & $\mathrm{MW}=0.34$ \\
\hline GI5 Preoccupation & $3(3) \mathrm{I}-5$ & $2(2) I-5$ & $M W=0.12$ \\
\hline $\begin{array}{l}\text { GI6 Active social } \\
\text { avoidance }\end{array}$ & $|(2)|-3$ & $2(2) I-6$ & $M W=0.15$ \\
\hline
\end{tabular}

Note: Bold represents a statistically significant value.

Abbreviations: bvFTD, behavioral variant frontotemporal dementia; IQR, interquartile range; MW, Mann-Whitney U-test.
General psychopathological symptoms in bvFTD patients versus patients with psychiatric disorders

Specific symptoms from the general subscale of the PANSS did not distinguish patients with probable and definite bvFTD from patients with a psychiatric disorder. Nonetheless, the total score of the general subscale of the PANSS was significantly higher in patients with a psychiatric disorder than in patients with bvFTD (32.0 versus 28.0, $P=0.046$ ). Patients with a psychiatric disorder were characterized by anxiety ( $\mathrm{OR}=0.32,95 \% \mathrm{CI}=0.14-0.72, P=0.006$ ), guilt feelings $(\mathrm{OR}=0.41,95 \% \mathrm{CI}=0.20-0.84, P=0.015)$, and tension $(\mathrm{OR}=0.26,95 \% \mathrm{CI}=0.12-0.58, P=0.001)$, which distinguished them from bvFTD patients.

\section{Predictive symptoms}

The combined predictors difficulty in abstract thinking, stereotypical thinking, anxiety, guilt feeling, and tension explained $75.4 \%$ of the variance in the diagnosis of bvFTD versus psychiatric diagnoses $\left(\chi^{2}=32.26, d f=5, P<0.001\right)$.

Multivariate logistic regression showed that patients with an increased tension (score $\geq 3$ ) had a significantly higher chance of having a psychiatric disorder and a lower chance of having bvFTD $(\mathrm{OR}=0.18,95 \% \mathrm{CI}=0.05-0.75, P=0.02)$.

\section{Discussion}

This is the first study thoroughly exploring the broad spectrum of psychotic symptoms in bvFTD patients, revealing that $95.5 \%$ of bvFTD patients exhibited at least one psychotic symptom, although not commonly the typical positive psychotic symptoms (ie, delusions, hallucinations, and suspiciousness), but formal thought disorders and negative psychotic symptoms such as social and emotional withdrawal and blunted affect. Difficulty in abstract thinking and stereotypical thinking differentiated bvFTD patients from patients with a psychiatric diagnosis in this well-phenotyped cohort of patients exhibiting a frontal lobe syndrome. Patients with a psychiatric diagnosis were characterized by the presence of anxiety, guilt feelings, and tension (general subscale), which distinguished them from bvFTD patients.

Despite frequent misdiagnosis with schizophrenia, the finding that bvFTD patients were not mainly characterized by typical positive psychotic symptoms (ie, hallucinations, delusions, and suspiciousness/paranoia) was partially in line with the previous studies. It has been found that although FTD can mimic schizophrenia, it rarely manifests with delusions and hallucinations. ${ }^{16,31-34}$ In a clinicopathological investigation and 
Table 3 Univariate logistic regression and forward multivariate logistic regression

\begin{tabular}{|c|c|c|c|c|}
\hline \multirow[t]{2}{*}{ Items PANSS } & \multicolumn{2}{|c|}{ Univariate logistic regression } & \multicolumn{2}{|c|}{ Multivariate logistic regression } \\
\hline & OR (95\% Cl) & $P$-value & OR $(95 \% \mathrm{Cl})$ & $P$-value \\
\hline Difficulty in abstract thinking & $1.86(1.22-2.84)$ & 0.004 & $1.62(0.84-3.12)$ & 0.15 \\
\hline Stereotyped thinking & $1.83(1.21-2.76)$ & 0.004 & $1.74(0.82-3.68)$ & 0.15 \\
\hline Anxiety & $0.32(0.14-0.72)$ & 0.006 & I.77 (0.44-7.09) & 0.42 \\
\hline Guilt feeling & $0.4 I(0.20-0.84)$ & 0.015 & $0.53(0.23-1.23)$ & 0.14 \\
\hline Tension & $0.26(0.12-0.58)$ & 0.001 & $0.18(0.05-0.75)$ & 0.02 \\
\hline
\end{tabular}

Notes: Dependent variable: psychiatric diagnosis $=0$, probable and definite bvFTD $=\mathrm{I}$. Bold represents a statistically significant value.

Abbreviations: bvFTD, behavioral variant frontotemporal dementia; Cl, confidence interval; OR, odds ratio; PANSS, Positive and Negative Symptom Scale.

review of cases, it was found that delusions, hallucinations, and paranoia are mainly present in young-onset FTD (in up to a third of bvFTD patients aged $\leq 30$ years). ${ }^{3}$ This may partly explain why the authors found a lower prevalence (22.7\%) in the present cohort, which was characterized by a higher mean age of bvFTD patients ( 58.95 years). A recent retrospective study on delusions, hallucinations, and paranoid ideas in neuropathologically verified bvFTD patients also revealed a relatively high prevalence of these positive psychotic symptoms (32\%): $20.6 \%$ of the patients had paranoid ideas, and $17.5 \%$ had hallucinations and delusions in equal measure. ${ }^{17}$ As discussed by the authors of this study, psychotic symptoms may be present for only a short period or occur later during disease course, thereby explaining the relatively high rates in their retrospective study. The variation in the prevalence of positive psychotic symptoms in different studies may also be associated with sample size. An association with the amount of genetic mutations cannot be excluded. Psychotic symptoms have repeatedly been described in progranulin and C9ORF72 mutation carriers..$^{24,28,35,36}$ As the present study cohort contained only three patients with a genetic mutation (13.6\% of bvFTD patients), the percentage of known genetic variants was lower compared to other studies $(\sim 20 \%-50 \%$ of hereditary etiologies found in other studies). ${ }^{37,38}$

It is noteworthy that bvFTD patients in the present study tend to have a lower total score at the positive subscale of the PANSS than that found in studies on schizophrenia (9.5 in bvFTD patients in the present study versus 18.2 in schizophrenia patients). ${ }^{20}$ This suggests that these positive psychotic symptoms are not the most prominent symptoms in the clinical overlap of bvFTD and psychotic disorders.

Interestingly, it was found that the median score on the negative subscale of the PANSS was significantly higher in patients with bvFTD than in patients with a psychiatric diagnosis (predominantly mood disorders) in the present LOF cohort, but comparable to patients with schizophrenia as measured previously. ${ }^{20}$ This finding suggests that negative psychotic symptoms may have an important contributory role in psychotic misdiagnosis in bvFTD.
With a closer look at the specific negative psychotic symptoms that characterize bvFTD, it was found that the presence of blunted affect, emotional withdrawal, poor rapport, passive social withdrawal, difficulty in abstract thinking, and stereotypical thinking characterizes bvFTD. It has been described previously that stereotypies or compulsive acts are often among the earliest and most salient symptoms of bvFTD, and these symptoms evolved into the FTDC consensus criteria. ${ }^{25,39}$ Impairment of abstract thinking in bvFTD patients has been described previously as associated with the cognitive profile of predominately executive dysfunction in bvFTD. ${ }^{40}$ The discriminatory power of stereotypical thinking in bvFTD versus psychiatric disorders also fits with the finding of the present study concerning the total scores at SRI as discriminating between bvFTD patients and patients with a psychiatric disorder and with previous studies regarding the SRI in a similar cohort (submitted Vijverberg et al, 2016).

Beyond the original aim of the present study, it was found that patients with a psychiatric diagnosis had a higher total score at the general subscale of the PANSS and that the presence of anxiety, guilt feelings, and tension distinguished psychiatric patients from bvFTD patients in this LOF syndrome cohort. This suits with previous findings about psychiatric disorders, especially in mood disorders and anxiety disorders, as these features are all expressions of distress. ${ }^{41-43}$ This is the first time tension has been found as a predictor for a psychiatric diagnosis in a group of patients with lateonset behavioral disturbances. The low tension in bvFTD is probably associated with lack of distress of bvFTD patients. ${ }^{2}$ Impaired insight has been described as typical for bvFTD, and this also includes impairment in emotional awareness as defined by the lack of expression of concern of distress when confronted by difficulties. ${ }^{2}$

\section{Limitations}

There are some limitations in the present study. First of all, this study cannot draw conclusions about psychotic symptoms that differentiate bvFTD from schizophrenia. This 
limitation arises from the heterogeneity of the psychiatric patient group and the small number of schizophrenia patients in the LOF cohort. This is a consequence of the design that is symptom-based, not etiology-based. Nevertheless, it is also convinced that this symptom-based design is an advantage as it resembles clinical practice. Besides, it has been acknowledged that there is an overrepresentation of psychotic symptoms in bvFTD patients with a known genetic background. ${ }^{24,35,36}$ An advantage is that the present cohort represented daily clinical practice as it was not enriched for genetic bvFTD. As a consequence, only three patients with a genetic mutation were included in the cohort, and it was not possible to do statistical analyses on these patients in particular. Another limitation is that neuropathological confirmation was obtained in only one bvFTD case. The diagnostically gold standard of 2 years approximates diagnostic certainty, but misdiagnosis after 2 years of diagnostic follow-up cannot be excluded.

Acknowledging the limitations, this is the first study systematically and prospectively subtyping the broad spectrum of psychotic and general symptoms in bvFTD patients and patients with a psychiatric diagnosis within a LOF cohort. Data from this study indicate that classic psychotic symptoms are infrequently present in bvFTD; however, negative psychotic symptoms such as social and emotional withdrawal, blunted affect, and formal thought disorders are present. It suggests that negative psychotic symptoms may contribute to the pitfall of psychotic misdiagnosis in bvFTD patients. Difficulty in abstract thinking and stereotypical thinking (negative subscale) are associated with probable and definite bvFTD, whereas anxiety, guilt feeling, and tension (general subscale) are associated with a psychiatric diagnosis. The combinations of these symptoms explained three-quarters of the variance in the diagnosis of bvFTD versus psychiatric diagnoses. Misdiagnosis in bvFTD patients can therefore be reduced by systematically exploring the broad spectrum of psychiatric symptoms.

\section{Acknowledgments}

The abstract of this paper was presented at the 10th International Conference on Frontotemporal Dementias Munich/Germany, August 31-September 2, 2016, as an abstract with interim findings. The abstract was published in the Journal of Neurochemistry.

\section{Disclosure}

Welmoed Krudop received funding from the Mooiste Contact Fonds, KPN. Philip Scheltens received grant support (for the institution: the VUmc, Alzheimer center) from GE
Healthcare, Danone Research, and MERCK. He has received speaker's fees (paid to the institution) from Lilly, GE Healthcare, Lundbeck, Danone, and Jansen AI-Pfizer. Yolande AL Pijnenburg received funding from the Nederlandse Hersenstichting. The other authors report no conflicts of interest in this work.

\section{References}

1. Mendez MF, McMurtray A, Chen AK, Shapira JS, Mishkin F, Miller BL. Functional neuroimaging and presenting psychiatric features in frontotemporal dementia. J Neurol Neurosurg Psychiatry. 2006;77:4-7.

2. Snowden JS, Neary D, Mann DM. Frontotemporal dementia. $\mathrm{Br} J$ Psychiatry. 2002;180:140-143.

3. Velakoulis D, Walterfang M, Mocellin R, Pantelis C, McLean C. Frontotemporal dementia presenting as schizophrenia-like psychosis in young people: clinicopathological series and review of cases. $\mathrm{Br} J$ Psychiatry. 2009;194(4):298-305.

4. Piguet O, Hornberger M, Mioshi E, Hodges JR. Behavioural-variant frontotemporal dementia: diagnosis, clinical staging, and management. Lancet Neurol. 2011;10(2):162-172.

5. Woolley JD, Khan BK, Murthy NK, Miller BL, Rankin KP. The diagnostic challenge of psychiatric symptoms in neurodegenerative disease; rates of and risk factors for prior psychiatric diagnosis in patients with early neurodegenerative disease. J Clin Psychiatry. 2011;72(2): 126-133.

6. Ducharme S, Price BH, Larvie M, Dougherty DD, Dickerson BC. Clinical approach to the differential diagnosis between behavioral variant frontotemporal dementia and primary psychiatric disorders. Am J Psychiatry. 2015;172(9):827-837.

7. Da Ponte G, Paiva A, Lobo M, Mendes S, Fernandes S. Mania like symptoms in frontotemporal dementia. Eur Psychiatry. 2010; 25:563.

8. Stone J, Griffiths TD, Rastogi S, Perry RH, Cleland PG. Non-Pick's frontotemporal dementia imitating schizophrenia in a 22-year-old man. J Neurol. 2003;250:369-370.

9. Ropacki SA, Jeste DV. Epidemiology of and risk factors for psychosis of Alzheimer's disease: a review of 55 studies published from 1990-2003. Am J Psychiatry. 2005;162:2022-2030.

10. Cagnin A, Gnoato F, Jelcic N, et al. Clinical and cognitive correlates of visual hallucinations in dementia with Lewy bodies. J Neurol Neurosurg Psychiatry. 2013;84(5):505-510.

11. American Psychiatric Association. Diagnostic and Statistical Manual of Mental Disorders (DSM). Washington, DC: American psychiatric association, 1994.

12. Gaebel W, Zielasek J. Focus on psychosis. Dialogues Clin Neurosci. 2015;17(1):9-18.

13. Harvey PD, Walker E. Positive and Negative Symptoms in Psychosis: Description, Research, and Future Directions. New Jersey: Routledge, 2013.

14. Holshausen K, Harvey PD, Elvevåg B, Foltz PW, Bowie CR. Latent semantic variables are associated with formal thought disorder and adaptive behavior in older inpatients with schizophrenia. Cortex. 2014; 55:88-96.

15. Mendez MF, Perryman KM. Neuropsychiatric features of frontotemporal dementia: evaluation of consensus criteria and review. J Neuropsychiatry Clin Neurosci. 2002;14(4):424-429.

16. Mendez MF, Shapira JS, Woods RJ, Licht EA, Saul RE. Psychotic symptoms in frontotemporal dementia: prevalence and review. Dement Geriatr Cogn Disord. 2008;25(3):206-211.

17. Landqvist Waldö M, Gustafson L, Passant U, Englund E. Psychotic symptoms in frontotemporal dementia: a diagnostic dilemma? Int Psychogeriatr. 2015;27(04):531-539.

18. Weder ND, Aziz R, Wilkins K, Tampi RR. Frontotemporal dementias: a review. Ann Gen Psychiatry. 2007;6:15. 
19. Swartz JR, Miller BL, Lesser IM, et al. Behavioral phenomenology in Alzheimer's disease, frontotemporal dementia and late-life depression: a retrospective analysis. J Geriatr Psychiatry Neurol. 1997;10: $67-74$.

20. Khan BK, Woolley JD, Chao S, et al. Schizophrenia or neurodegenerative disease prodrome? Outcome of a first psychotic episode in a 35-year old woman. Psychosomatics. 2012;53(3):280-284.

21. Krudop WA, Kerssens CJ, Dols A, et al. Building a new paradigm for the early recognition of behavioral variant frontotemporal dementia: late onset frontal lobe syndrome study. Am J Geriatr Psychiatry. 2014; 22(7):735-740.

22. Dols A, van Liempt S, Gossink F, et al. Identifying specific clinical symptoms of behavioral variant frontotemporal dementia versus differential psychiatric disorders in patients presenting with a late-onset Frontal Lobe Syndrome. J Clin Psychiatry. 2016;77(10):1391-1395.

23. Rascovsky K, Hodges JR, Knopman D, et al. Sensitivity of revised diagnostic criteria for the behavioural variant of frontotemporal dementia. Brain. 2011;134(9):2456-2477.

24. Galimberti D, Fenoglio C, Serpente M, et al. Autosomal dominant frontotemporal lobar degeneration due to the C9ORF72 hexanucleotide repeat expansion: late-onset psychotic clinical presentation. Biol Psychiatry. 2013;74(5):384-391.

25. Keshavan MS, Rabinowitz J, DeSmedt G, Harvey PD, Schooler N. Correlates of insight in first episode psychosis. Schizophr Res. 2004; 70(2):187-194.

26. Kay SR, Fiszbein A, Opler LA. The positive and negative syndrome scale (PANSS) for schizophrenia. Schizoph Bull. 1987;13(2):261-276.

27. Milak MS, Aniskin DB, Eisenberg DP, et al. The negative syndrome as a dimension: factor analyses of PANSS in major depressive disorder and organic brain disease compared with negative syndrome structures found in the schizophrenia literature. Cogn Behav Neurol. 2007;20(2): $113-120$.

28. Shinagawa S, Naasan G, Karydas AM, et al. Clinicopathological study of patients with C9ORF72-associated frontotemporal dementia presenting with delusions. J Geriatr Psychiatry Neurol. 2015;28(2):99-107.

29. Figuerido JL, Gutiérrez M, González PA, et al. Predictors of rehospitalization in schizophrenia. Actas Luso Esp Neurol Psiquiatr Cienc Afines. 1996;25(4):217-224. Spanish.

30. Kay SR, Opler LA, Fiszbein A. Positive and Negative Syndrome Scale (PANSS) Rating Manual. Social and Behavioral Sciences Documents. San Rafael, CA: Schizophrenia bulletin. 1987.
31. Le Ber I, Guedj E, Gabelle A, et al. Demographic, neurological and behavioural characteristics and brain perfusion SPECT in frontal variant of frontotemporal dementia. Brain. 2006;129(11):3051-3065.

32. Gregory CA. Frontal variant of frontotemporal dementia: a crosssectional and longitudinal study of neuropsychiatric features. Psychol Med. 1999;29(5):1205-1217.

33. Passant U, Elfgren C, Englund E, Gustafson L. Psychiatric symptoms and their psychosocial consequences in frontotemporal dementia. Alzheimer Dis Assoc Disord. 2005;19:S15-S18.

34. Mendez MF, Lauterbach EC, Sampson SM. An evidence-based review of the psychopathology of frontotemporal dementia: a report of the ANPA Committee on Research. J Neuropsychiatry Clin Neurosci. 2008; 20:130-149

35. Urwin H, Josephs KA, Rohrer JD, et al. FUS pathology defines the majority of tau- and TDP-43-negative frontotemporal lobar degeneration. Acta Neuropathol. 2010;120(1):33-41.

36. Kertesz A, Ang LC, Jesso S, et al. Psychosis and hallucinations in FTD with C9ORF72 mutation: a detailed clinical cohort. Cogn Behav Neurol. 2013;26(3):146-154.

37. Rohrer JD, Guerreiro R, Vandrovcova J, et al. The heritability and genetics of frontotemporal lobar degeneration. Neurology. 2009;73(18): 1451-1456.

38. Rohrer JD, Warren JD. Phenotypic signatures of genetic frontotemporal dementia. Curr Opin Neurol. 2011;24(6):542-549.

39. Luzzi S, Fabi K, Pesallaccia M, Cafazzo V, Silvestrini M, Provinciali L. To clap or not to clap? Applause sign in apathetic and disinhibited/stereotypical behavioural variants of FTD. JNeurol Neurosurg Psychiatry. 2014;85(7):823-824.

40. Poletti M, Lucetti C, Logi C, et al. Cognitive correlates of negative symptoms in behavioral variant frontotemporal dementia: implications for the frontal lobe syndrome. Neurological Sci. 2013;34:1893-1896.

41. Watson D, Clark LA, Carey G. Positive and negative affectivity and their relation to anxiety and depressive disorders. J Abnorm Psychol. 1988;97(3):346-353.

42. Gilbert P. The relationship of shame, social anxiety and depression: the role of the evaluation of social rank. Clin Psychol Psychother. 2000;7(3):174-189.

43. World Health Organization. The ICD-10 classification of mental and behavioural disorders: clinical descriptions and diagnostic guidelines. Geneva: World Health Organization. 1992.
Neuropsychiatric Disease and Treatment

\section{Publish your work in this journal}

Neuropsychiatric Disease and Treatment is an international, peerreviewed journal of clinical therapeutics and pharmacology focusing on concise rapid reporting of clinical or pre-clinical studies on a range of neuropsychiatric and neurological disorders. This journal is indexed on PubMed Central, the 'PsycINFO' database and CAS,

\section{Dovepress}

and is the official journal of The International Neuropsychiatric Association (INA). The manuscript management system is completely online and includes a very quick and fair peer-review system, which is all easy to use. Visit http://www.dovepress.com/testimonials.php to read real quotes from published authors. 